Received Date : 09-Sep-2016

3

Revised Date : 02-Nov-2016

4

Accepted Date : 16-Nov-2016

5

Article type : Clinical investigation

6

7

\title{
Adductor Canal Blocks: Changing Practice Patterns and Associated Quality Profile
}

Short / Running Title:

Authors:
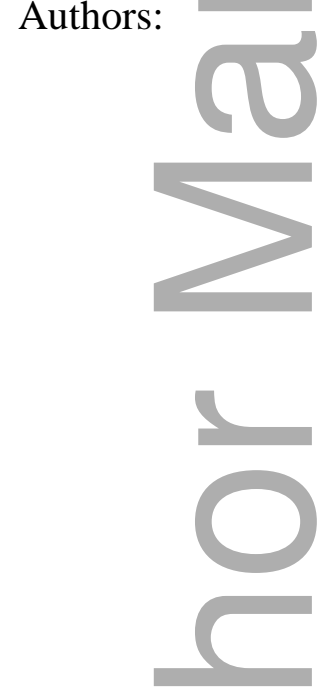

Institution:

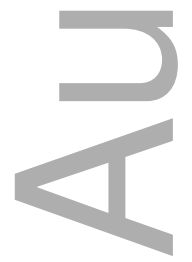

Adductor Canal Blocks: Changing Practice

Melissa M. Masaracchia ${ }^{1}$

Michael D. Herrick ${ }^{1}$

Michael Barrington ${ }^{2}$

Patrick R. Hartmann ${ }^{1}$

Brian D. Sites ${ }^{1}$

1. Department of Anesthesiology and Pain Medicine Dartmouth-Hitchcock Medical Center, Lebanon, NH 1 Medical Center Drive Lebanon, New Hampshire 03756, USA

2. Department of Anesthesia and Acute Pain Medicine

This is the author manuscript accepted for publication and has undergone full peer review but has not been through the copyediting, typesetting, pagination and proofreading process, which may lead to differences between this version and the Version of Record. Please cite this article as doi: $\underline{10.1111 / a a s .12845}$

This article is protected by copyright. All rights reserved 


\section{University of Melbourne}

41 Victoria Parade Fitzroy, 3065, Australia

Correspondence:
Department/Institutio
Acknowledgments

Financial Sources:

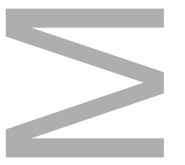

Conflicts of Interest:

Presentation:

1

ABSTRACT

2 Background:
Melissa M. Masaracchia

Melissa.m.masaracchia@hitchcock.org

Tel: (603) 650-6719

Fax: (603) 650-8980

Department of Anesthesiology and Pain Management

Dartmouth-Hitchcock Medical Center
Funded by non-clinical time from the Department of

Anesthesiology at Dartmouth-Hitchcock Medical Center

None

Abstract presented at ASRA 2016, IARS 2016.

3 Femoral nerve blocks have been the gold standard approach for post-operative analgesia

4 following total knee arthroplasty; however, the adductor canal block has recently gained

5 popularity due to less block-induced motor weakness. The primary aim of this time-series

6 analysis was to identify whether regional anesthesia practice changes have occurred for total 
1 knee arthroplasty. Our secondary aim was to assess for possible associated changes in safety and

2 quality.

3 Methods:

4 Using a 20-member clinical registry, we examined the practice patterns and safety around the

5 performance of adductor canal blocks for all total knee arthroplasties between July 18, 2011 to

6 October 9, 2015. To obtain more information about changes in quality associated with this

7 practice transition, we analyzed clinical outcomes data surrounding all primary total knee

8 arthroplasties from the largest contributing institution.

9 Results:

6,921 blocks were performed for 4,822 primary and revision TKAs. Across the registry, adductor canal block utilization for TKA increased. This was not associated with any increase in

12 immediate or recovery room related complications. When analyzing unilateral primary TKAs

13 from the largest surgical volume center $(n=766)$, there were no statistically significant changes in 14 numeric rating scale scores $(5.4$ to $4.6, \mathrm{p}$ value $=0.004)$, length of stay $(3.0$ to 2.8 days, $\mathrm{p}$ value $=$ $150.3)$, or 30 -day hospital revaluations for pain $(2.8 \%$ to $4.9 \%$, $\mathrm{p}$ value $=0.1)$.

16 Conclusion:

17 There was a large increase in the utilization of ACB for TKAs among participating registry 18 members. This change in practice was not associated with significant changes in safety or 19 quality.

20 Editorial Comment:

21 This clinical registry report demonstrates a large increase in the utilization of Adductor Canal 22 Blockade (ACB) for postoperative analgesia after total knee arthroplasty. The observed change 23 in practice was not associated with significant changes in safety or quality.

\section{INTRODUCTION}

25 Effective postoperative analgesia is important for functional recovery after total knee 26 arthroplasty (TKA). Peripheral regional anesthesia involving the femoral nerve has been the gold 27 standard non-opioid based approach for nearly two decades. Femoral nerve blocks (FNB) have 
1 been shown to improve analgesia in comparison to intravenous patient-controlled analgesia 2 (PCA) or epidural alone. ${ }^{1}$

3 The major limitation of FNB for TKA is the development of quadriceps muscle weakness, which

4 has been illustrated in several studies by quantifying strength, or lack thereof, with objective 5 measure through a dynamometer. ${ }^{6}$ FNB-induced quadriceps weakness may hamper rapid

6 hospital discharge and contribute to delays in physical therapy and patient falls. ${ }^{2-7}$ These quality 7 concerns have generated interest in regional anesthesia techniques that provide non-inferior 8 analgesia while minimizing muscle weakness. ${ }^{4-7}$ One such approach, the adductor canal block

9 (ACB), has gained popularity since it is thought to provide adequate sensory blockade while 10 sparing motor innervation. ${ }^{6,7}$ The ACB involves the injection of local anesthesia into the sub11 sartorial fascial planes in the mid-thigh. ${ }^{8}$ Although uncertainty surrounds the exact mechanism(s) 12 of analgesia from an ACB, the block has been found to provide non-inferior analgesia compared to a FNB following TKA., ${ }^{9,10}$

14 With regard to regional anesthesia, little information exists on how rapidly new techniques are adopted into clinical practice following evidence-based research that justifies its application in academic centers. Given the aforementioned benefits of an ACB when compared to the previous gold standard (FNB), we hypothesized that ACB utilization has increased within the regional anesthesia community. Using a multi-institutional clinical registry, the International Registry of Regional Anesthesia (IRORA - Appendix 1), our primary aim was to identify whether or not practice changes have occurred around the performance of FNB compared to ACB. Additionally, if practice changes have occurred, our secondary aim was to assess for possible associated 22 changes in safety or quality.

\section{METHODS}

24 The Dartmouth Committee for Protection of Human Subjects granted ethical approval for the study (CPHS\#: STUDY00028930; approved by Jeremy van Hoff on 16 September 2015; 63 South Main Street, Hanover, NH 03755, USA).

27 The IRORA database uses a web-based interface to facilitate the collection and entry of data on

28 quality of clinical practice where peripheral nerve blocks are performed. ${ }^{11}$ During this study 29 period there were 20 contributing institutions. This registry has previously reported outcomes 
1 including neurological and respiratory complications, local anesthetic systemic toxicity, patient

2 satisfaction, and has been used to identify targets for quality improvement. Features of this

3 clinical registry include: (1) a waiver of the entire consent process for data collection so that all

4 eligible patients are captured minimizing selection bias; (2) a web-based data collection interface

5 providing the ability to gather de-identified information (including demographics, block

6 characteristics, and block-related morbidity events) from a large number of patients (each patient

7 assigned an ID number); (3) a systematic process to ensure postoperative contact with all

8 patients; (4) a defined follow-up and investigative pathway; (5) a clear definition and verification

9 of all key outcomes; and (6) a data quality assurance process that includes site visits, interviews, and chart reviews.

11 The IRORA database was interrogated to conduct a time-series analysis examining the practice

12 patterns around the performance of ACBs for all total knee arthroplasties (primary, revision and

13 bilateral) between July 18, 2011 to October 9, 2015. Simple descriptive statistics were used to summarize block characteristics by hospital identifier. In order to gain insight into ACB performance and safety over time for the entire registry, we examined select variables using statistical process control (SPC) charts. SPC charts enrich simple aggregate data by examining temporal variation. Using standard SPC methods, we examined for special cause signals, which, if present, would suggest that the process is not in statistical control. ${ }^{12,13}$

19 Using a p chart, we first explored whether or not utilization of ACBs changed for members of IRORA during the study period. This time block was further broken down into seventeen time intervals of approximately three months, which served as the unit of analysis for the SPC charts.

22 Using a U-chart, we tracked total block related complications during this same time period for 23 the entire registry. ${ }^{11}$ Complications [immediate and in the post-anesthesia care unit (PACU)] 24 include adverse events that occurred immediately after block placement as well as in the 25 recovery room. These included unintended venous or arterial puncture, paresthesia, seizure, respiratory depression or compromise, pneumothorax, cardiac arrest, and fall events. ${ }^{14}$

27 IRORA does not currently track clinical outcomes related to health care quality beyond standard nerve block characteristics and complications. Thus, in order to gain insight into all possible changes (negative or positive) in quality associated with a changing ACB practice, we analyzed clinical outcomes data from a single member institution (Dartmouth-Hitchcock Medical Center 
1 [DHMC]) that performs the largest volume of TKAs. DHMC was also chosen for quality 2 analysis because, per clinical pathway, only one block is performed for each TKA. This simplifies the analysis and minimizes confounders when comparing a before and after time 4 period around the transition from FNB to ACB. DHMC is a tertiary care academic medical 5 center located in New Hampshire, U.S.A. The inclusive dates for the DHMC subset analysis was June 1, 2013 through June 1, 2015. For this analysis, a before and after time period was created and defined by the date when a clinical pathway was established at DHMC to replace FNBs with ACBs (policy launch June $1^{\text {st }}, 2014$ ). This policy was instituted after newly established research suggested that ACBs provide non-inferior analgesia when compared to FNBs, and have fewer associated complications (decreased quadriceps weakness, decreased length of stay). ${ }^{4-7,9,10}$ At DHMC, ACB are performed by entering into the sub-sartorial fascial plane in the mid-thigh and typically inject $15-30 \mathrm{~mL}$ of ropivacaine $0.35-0.5 \%$. Beyond the transition from FNB to ACB, no other changes were made to the multi-modal analgesic pathway. The hospital's electronic medical record (Epic Systems Corporation; Madison, WI) was used to gather specific quality pain, and $10=$ worst imaginable pain) in the PACU, hospital length of stay, 30-day hospital reevaluation rates due to pain, and inpatient fall events. ${ }^{15}$ The registered nurse caring for the patient in the PACU documented scores throughout the patient's recovery room stay. Inpatient fall events were recognized by querying Quantros (Quantros Inc.; Milpitas, CA), a third party server that tracks hospital-wide patient safety events. Thirty-day hospital reevaluation was defined as any patient discharged from their index TKA and then admitted to the hospital or reevaluated in the emergency room for treatment of pain related to their surgical site exceeding the analgesic benefit of prescribed opioids. The electronic medical record (EMR) was used to flag all thirty-day hospital readmissions and then a manual chart review was performed to establish whether the patient was readmitted for pain as per the aforementioned definition (Appendix 2).

For this aggregate comparison, binary data were analyzed with the $\chi^{2}$. Continuous data were analyzed using a two-sample t-test. For aggregate comparisons, alpha was set at 0.01 to adjust for multiple comparisons. To characterize analgesic quality over time for DHMC, we also explored NRS scores using a XmR moving range chart to search for special cause signals. ${ }^{13}$ 


\section{RESULTS}

During the period of study, 4,822 total knee replacements and 6,921 blocks were performed for primary and revision TKAs in the entire registry. 342 patients had a bilateral TKA and 348 patients underwent revision TKA. There were 1,425 TKAs patients that received a combination of two or more blocks for postoperative analgesia (accounting for the finding of more blocks than patients recorded). For example, a patient could receive a combination of two or more blocks (femoral and sciatic) for post-operative analgesia. For the quality analysis using DHMC patients, there were no patients that had two or more blocks. This reflects the clinical practice at DHMC of offering only a single block consisting of either a femoral or adductor canal block.

The majority of TKAs (77.8\%) occurred at four hospitals: 1, 3, 11, and 15 (Table 1). DHMC represents the largest surgical volume and was identified as hospital 15. Table 1 summarizes, by hospital, the types of peripheral blocks placed for TKA. There is notable variation in practice regarding types of blocks and procedural volumes between institutions, although FNB and ACB constitute the majority in most cases.

Figure 1 is a p chart demonstrating a significant increase in the utilization of ACBs collectively for the entire registry. A special cause signal (value above 3 sigmas of the running average) is identified at time-period 13, representing the changing practice pattern. Despite this substantial increase in $\mathrm{ACB}$ utilization, the types of complications and the complication rate for the entire registry remained relatively unchanged. This stability is reflected in a U-chart (Figure 2) summarizing the total number of PACU and immediate complications per 100 blocks for IRORA over time. There were no special cause signals, suggesting that the process was stable.

For the DHMC subset analysis, 766 primary unilateral TKAs were analyzed (Table 2). The mean age was 64.8 years (SD 10.3); the mean body mass index was 32.9 (SD 7.9); and the proportion of females was 0.57. ACBs at DHMC were performed with the injection of local anesthesia into the sub-sartorial fascial planes in the mid-thigh using 15-30 mls (mean $27.4 \mathrm{~mL}$ ) of ropivacaine 0.35-0.5\%. Femoral nerve blocks included both single shot blocks and continuous catheters.

For the post-policy time period (Table 2), there were no statistically significant changes in DHMC reported mean PACU NRS pain scores $(5.4$ to $4.6, \mathrm{p}$ value $=0.004)$, length of stay $(3.0$ to 2.8 days, $\mathrm{p}$ value $=0.3), 30$-day hospital revaluations for pain $(2.8 \%$ to $4.9 \%, \mathrm{p}$ value $=0.1)$, 
or inpatient fall events ( 1 to $0, \mathrm{p}$ value $=0.3$ ). Figure 3 is the $\mathrm{XmR}$ chart for DHMC summarizing average NRS score and reveals no special cause signals.

There were a total of 34 patients who had re-evaluations for pain in our cohort of 766 patients having unilateral primary TKA at DHMC. Of these 34 patients, 11 occurred in the pre-policy period with all having a femoral nerve block. There were 18 patients in the post-policy period who experienced a re-evaluation for pain, of which 17 received an adductor canal block and 1 received a femoral nerve block. The details of these patients can be found in Appendix 2.

\section{DISCUSSION}

We found a large increase in the utilization of ACBs among the participating members of the IRORA. This increase was not associated with a significant change in the rate of immediate or PACU related block complications as assessed for the 20-member registry. Additionally, when analyzing data from the largest volume center, we did not find clinically relevant changes in various standard quality metrics. Although there was a trend toward higher re-evaluations for pain following discharge, detailed chart reviews of these patients suggests that variable(s) unrelated to regional anesthesia were likely involved. For instance, there were three patients who presented with severe pain related to hemarthrosis, which is clearly unrelated to the anesthetic approach.

The Pediatric Regional Anesthesia Network (PRAN) is a multi-institutional registry that has evaluated safety and evolving practice patterns in pediatric anesthesia. ${ }^{16}$ For adult patients, IRORA shares many of the same scholastic objectives as PRAN. Such research and analysis will likely be progressively important as the perioperative surgical home model matures. ${ }^{17,18}$ The iterative process of making practice changes and assessing the impact on outcomes will facilitate the ability to provide high value care. We hope that the process of sharing data and outcomes used in this manuscript could serve as a framework upon which the anesthesia community can build.

Our time-series analysis constitutes an observational study subject to confounding. There are likely many variables changing in the various complex health systems that could have influenced the relationship between ACB performance and our outcome metrics. Although large randomized control trials are still considered the gold standard for evaluating changes in clinical 
1 practice and should be considered the highest level of evidence, we would like to emphasize that 2 our work provides a structure for how we can study safety and quality of regional 3 anesthesia and pain medicine as a community using large datasets. We also followed standard 4 methodological processes for analyzing and reporting quality data over time that have been 5 used commonly with lean six-sigma techniques to minimize bias. ${ }^{19}$ One possible confounder was 6 the changing frequency of patients receiving more than one nerve block (Appendix 3); however,

7 only unitary nerve blocks were used for DHMC, which was the reference center for the quality 8 analysis (Table 2), thus effectively eliminating this as a possibility.

9 In conclusion, we have summarized a changing clinical practice around the performance of 10 ACBs for TKA. From the data available to us, we can suggest that this changing practice has not been associated with clinically relevant degradations (or improvements) in safety or quality.

\section{REFERENCES:}

1. Paul JE, Aman A, Hurlburt L, Cheng J, Thabane L, Tidy A, Murthy Y; Femoral Nerve Block Improves Analgesia Outcomes after Total Knee Arthroplasty: A Meta-analysis of Randomized Controlled Trials. Anesthesiology 2010; 113: 1144-1162.

2. Sharma S, Iorio R, Specht LM, Lepie SD, Healy WL. Complications of Femoral Nerve Blocks for Total Knee Arthroplasty. Clin Orthop 2010; 468: 135-140.

3. Ludwigson JL, Tillmans SD, Galgon RE, Chambers TA, Heiner JP, Schroeder KM. A Comparison of Single-Shot Adductor Canal Block vs Femoral Nerve Catheter for Total Knee Arthroplasty. J Arthroplasty 2015; 30: 68-71.

4. Charous MT, Madison SJ, Suresh PJ, Sandhu NS, Loland VJ, Mariano ER, et al. Continuous femoral nerve blocks: varying local anesthetic delivery method (bolus versus basal) to minimize quadriceps motor block while maintaining sensory block. Anesthesiology 2011; 115: 774-781.

5. Ilfeld BM, Duke KB, Donohue MC. The association between lower extremity continuous peripheral nerve blocks and patient falls after knee and hip arthroplasty. Anesth Analg 2010; 111:1552-1554.

6. Jaeger P, Nielsen ZJ, Henningsen MH, Hilsted KL, Mathiesen O, Dahl JB. Adductor canal block versus femoral nerve block and quadriceps strength: a randomized, double- 
blind, placebo-controlled, crossover study in healthy volunteers. Anesthesiology 2013; 118: 409-415.

7. Kwofie MK, Shastri UD, Gadsden JC, Sinha SK, Abrams JH, Xu D, Salviz EA. The effects of ultrasound-guided adductor canal block versus femoral nerve block on quadriceps strength and fall risk: A blinded, randomized trial of volunteers. Reg Anesth 2013; 38:321-325.

8. Kapoor R, Adhikary SD, Siefring C, McQuillan PM. The saphenous nerve and its relationship to the nerve to the vastus medialis in and around the adductor canal: an anatomical study. Acta Anaesthesiol Scand 2012; 56: 365-367.

9. Jaeger P, Zaric D, Fomsgaard JS, Hilsted KL, Bjerregaard J, Gyrn J, Mathiesen O, Larsen TK, Dah1 JB. Adductor canal block versus femoral nerve block for analgesia after total knee arthroplasty: a randomized, double-blind study. Reg Anesth 2013; 38: 526-532.

10. Kim DH, Lin Y, Goytizolo EA, Kahn RL, Maalouf DB, Manohar A, Patt ML, Goon AK, Lee YY, Ma Y, Yadeau JT. Adductor canal block versus femoral nerve block for total knee arthroplasty: a prospective, randomized, controlled trial. Anesthesiology 2014; 120: $540-550$.

11. Barrington MJ. International Registry of Regional Anesthesia. Available at: http://www.anaesthesiaregistry.org; date accessed: 13 Jul 2012.

12. Benneyan J, Lloyd R, Plsek P. Statistical process control as a tool for research and healthcare improvement. Qual Saf Health Care. 2003; 12: 458-464.

13. Mohammed MA, Worthington P, Woodall WH. Plotting basic control charts: tutorial notes for healthcare practitioners. Qual Saf Health Care 2008; 17: 137-145.

14. Barrington M, Watts SA, Gledhill SR, Thomas RD, Said SA, Snyder GL, Jamrozik, KD. Preliminary Results of the Australasian Regional Anaesthesia Collaboration: A Prospective Audit of More Than 7000 Peripheral Nerve and Plexus Blocks for Neurologic and Other Complications. Reg Anesth 2009; 34: 534-541.

15. Krebs EE, Carey TS, Weinberger M. Accuracy of the Pain Numeric Rating Scale as a Screening Test in Primary Care. JGIM 2007; 1453-1458.

16. Polaner DM, Taenzer AH, Walker BJ, Bosenberg A, Krane EJ, Suresh S, Wolf C, Martin LD. Pediatric Regional Anesthesia Network (PRAN): a multi-institutional study of the 
use and incidence of complications of pediatric regional anesthesia. Anesth Analg 2012; 115: 1353-1364.

17. Shafer, SL; Donovan, JF. Anesthesia \& Analgesia's Collection on the Perioperative Surgical Home. Anesth Analg 2014; 118: 893-895.

18. Garson L; Schwarzkopf R; Vakharia, S; Alexander B; Stead S; Cannesson M; Kain Z. Implementation of a Total Joint Replacement-Focused Perioperative Surgical Home: A Management Case Report. Anesth Analg 2014; 118: 1081-1089.

19. Gupta BC; Walker HF. Applied Statistics For The Six Sigma Green Belt. 1st ed. Milwaukee, WI: America Society of Quality, Quality Press, 2005.

FIGURE LEGENDS:

2 Figure 1: Adductor canal blocks as a proportion of all blocks for the entire registry graphed on a $3 \mathrm{P}$ chart. Each time block indicates an interval of 3 months. The solid black line indicates the 4 running average. The dashed lines above and below the solid line signify the upper and lower 5 control limits, respectively. A special cause signal is identified at time period 13, representing a 6 significant increase in the utilization of adductor canal.

$7 \quad$ Figure 2: Total number of immediate complications per 100 blocks for IRORA graphed on a U 8 chart. The solid black line indicates the running average. The dashed line signifies the upper 9 control limit. There were no special cause signals, suggesting that the process is stable.

10 Figure 3: PACU pain scores over time at Dartmouth-Hitchcock Medical Center graphed on a $11 \mathrm{XmR}$ chart. The solid black line indicates the running average. The dashed lines above and 12 below the solid line signify the upper and lower control limit, respectively. The vertical arrow 13 indicates a change in practice to adductor canal blocks for total knee arthroplasty. There are no 14 special cause signals, suggesting that the process is stable. 
APPENDIX 1: Hospitals contributing to IRORA database

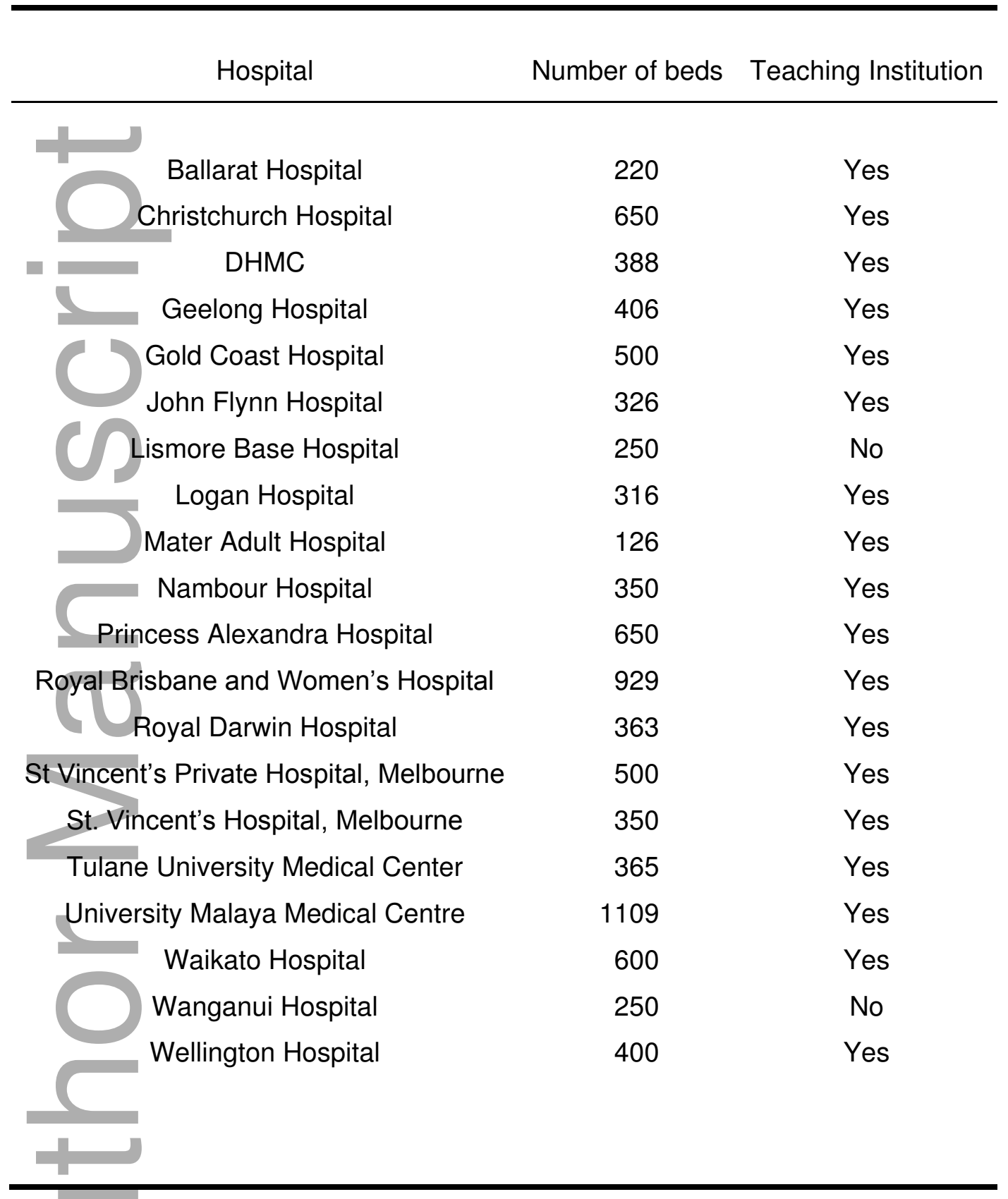


APPENDIX 2. Causes of Pain-Related Hospital Based Evaluation at DHMC within 4 weeks of discharge from index TKA

\begin{tabular}{|c|c|c|c|c|c|c|c|}
\hline Patient \# & Age & Sex & BMI & ASA & $\begin{array}{c}\text { Regional } \\
\text { Block }\end{array}$ & Associated findings & $\begin{array}{c}\text { Maximum } \\
\text { NRS } \\
\text { score in } \\
\text { ED }\end{array}$ \\
\hline 1 & 70 & $\mathrm{~F}$ & 33.8 & 2 & Femoral & Knee edema & 6 \\
\hline 2 & & $\mathrm{~F}$ & 36.3 & 2 & Adductor & Febrile, knee erythema & 3 \\
\hline 3 & 53 & $M$ & 52.4 & 3 & Adductor & Wound dehiscence & 4 \\
\hline 4 & & $M$ & 23.7 & 2 & Femoral & Hemarthrosis & 10 \\
\hline 5 & 63 & $M$ & 27.6 & 2 & Femoral & Hemarthrosis & 4 \\
\hline 6 & 67 & $\mathrm{~F}$ & 31 & 2 & Adductor & No other findings & 8 \\
\hline 7 & 70 & $\mathrm{~F}$ & 38.2 & 2 & Femoral & Knee erythema & 2 \\
\hline 8 & 67 & $\mathrm{~F}$ & 30 & 2 & Femoral & No other findings & 6 \\
\hline 9 & 66 & $\mathrm{~F}$ & 37.3 & 3 & Adductor & No other findings & 4 \\
\hline 10 & 63 & $M$ & 36 & 2 & Femoral & Knee edema & 4 \\
\hline 11 & 51 & $\mathrm{~F}$ & 22.5 & 1 & Femoral & Knee edema & 5 \\
\hline 12 & & $\mathrm{~F}$ & 36.9 & 3 & Femoral & No other findings & 9 \\
\hline 13 & 73 & $\mathrm{~F}$ & 35.8 & 2 & Adductor & No other findings & 7 \\
\hline 14 & 61 & $M$ & 43.5 & 3 & Femoral & No other findings & 7 \\
\hline 15 & 56 & $\mathrm{~F}$ & 21.5 & 3 & Femoral & Hemarthrosis & 10 \\
\hline 16 & 73 & $M$ & 26.5 & 2 & Adductor & No other findings & 6 \\
\hline 17 & & $\mathrm{~F}$ & 25.4 & 3 & Femoral & No other findings & 9 \\
\hline 18 & 55 & $\mathrm{~F}$ & 26.8 & 3 & Femoral & No other findings & 10 \\
\hline 19 & 50 & $\mathrm{~F}$ & 30.1 & 2 & Adductor & Deep venous thrombosis & 8 \\
\hline 20 & 65 & $\mathrm{~F}$ & 49.5 & 3 & Adductor & Deep venous thrombosis & 2 \\
\hline 21 & 71 & $\mathrm{~F}$ & 21.7 & 2 & Femoral & Knee edema, erythema & 6 \\
\hline 22 & 65 & $\mathrm{~F}$ & 28.8 & 2 & Adductor & No other findings & 10 \\
\hline 23 & 56 & $\mathrm{~F}$ & 22.5 & 2 & Adductor & Febrile & 3 \\
\hline 24 & 53 & $M$ & 23.1 & 2 & Adductor & No other findings & 5 \\
\hline 25 & 59 & $\mathrm{~F}$ & 43.2 & 3 & Femoral & Knee erythema & 8 \\
\hline 26 & 77 & $\mathrm{~F}$ & 26.4 & 2 & Adductor & Wound dehiscence & 5 \\
\hline 27 & 63 & $\mathrm{~F}$ & 29.1 & 3 & Adductor & No other findings & 10 \\
\hline
\end{tabular}




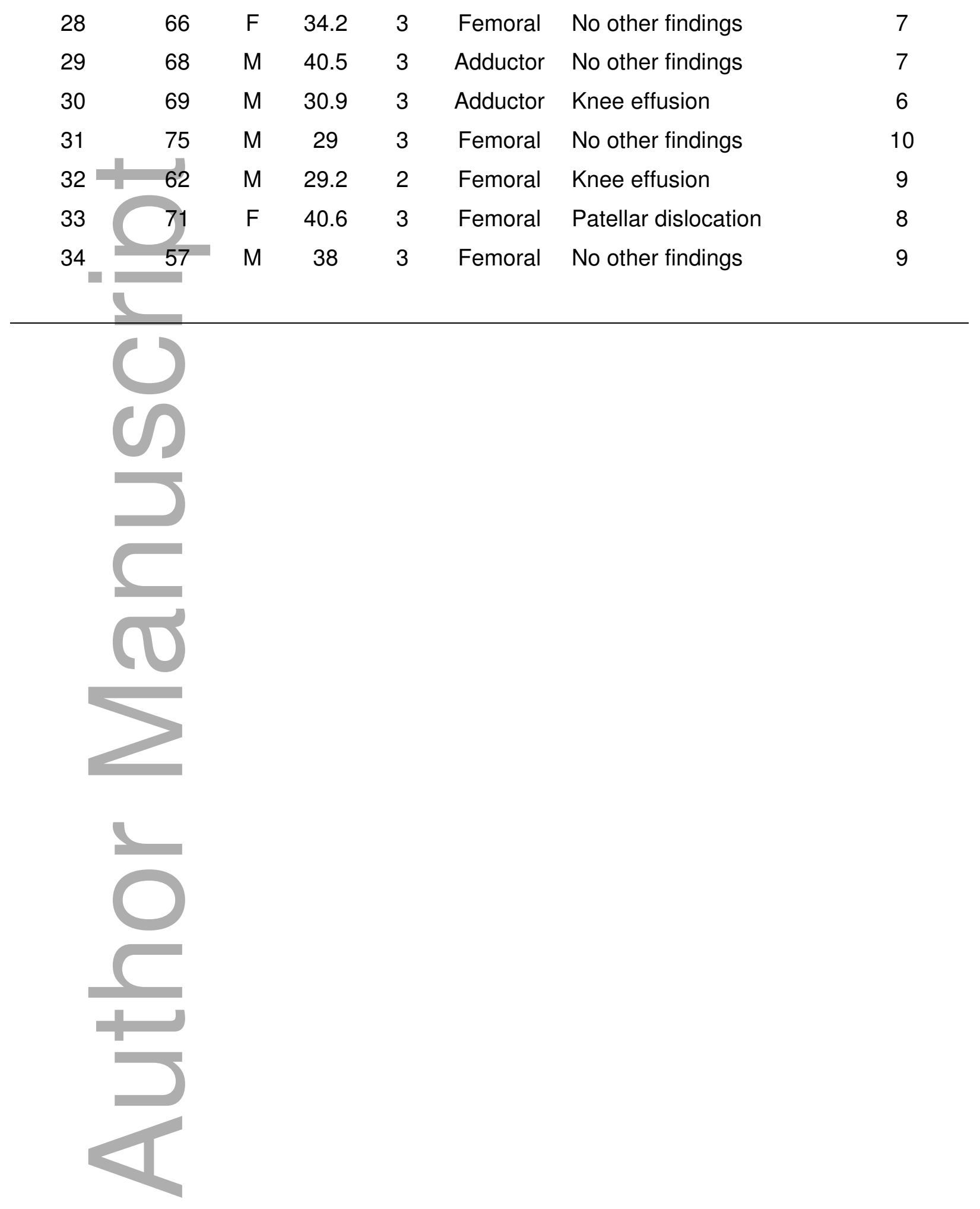

This article is protected by copyright. All rights reserved 
Table 1: Characteristics of regional anesthesia for TKA by hospitals in IRORA (2011-2015)

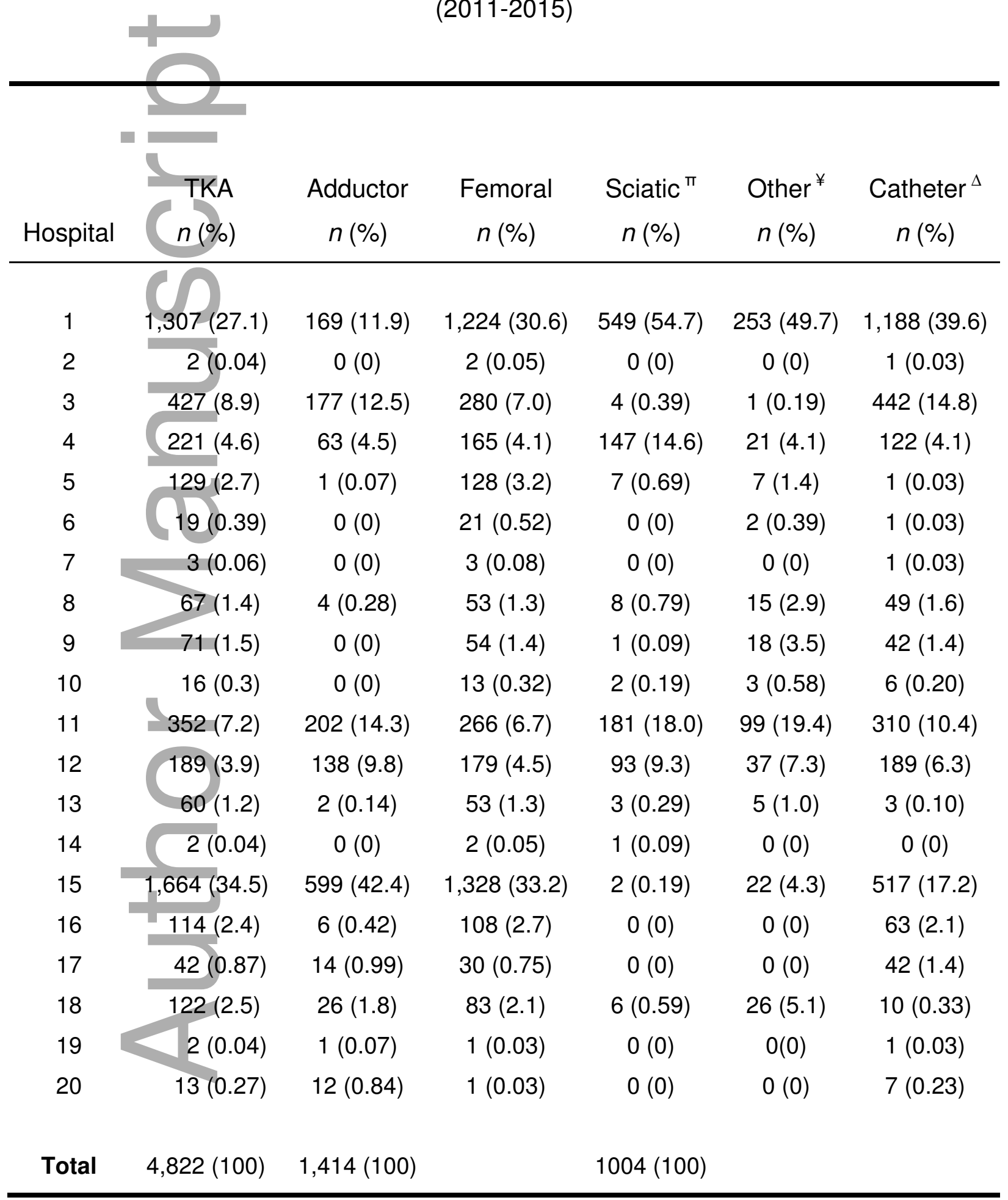


TKA = total knee replacement; includes primary unilateral and bilateral surgery, and revision

$\pi$ Sciatic block includes any approach from popliteal fossa to proximal gluteal region

${ }^{¥}$ Other block includes lateral femoral cutaneous, obturator, and lumbar plexus

${ }^{\Delta}$ Catheter refers to a continuous peripheral nerve block administered through a catheter
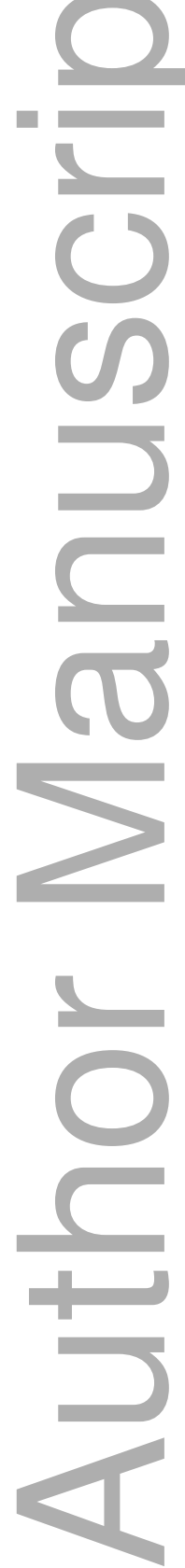

This article is protected by copyright. All rights reserved 
Table 2. Practice comparison between pre and post adductor canal policy change for DHMC for primary unilateral TKA

\begin{tabular}{|c|c|c|c|}
\hline r & $\begin{array}{l}\text { Pre-policy } \\
\qquad \begin{array}{l}\epsilon \\
=400\end{array}\end{array}$ & $\begin{array}{l}\text { Post-policy }{ }^{\epsilon} \\
N=366\end{array}$ & p value $\urcorner$ \\
\hline Adductor canal (n, \%) ${ }^{\pi}$ & $4,1.0 \%$ & $323,88.3 \%$ & $<0.001$ \\
\hline Femoral $(n, \%)^{\phi}$ & $396,99.0 \%$ & $43,11.7 \%$ & $<0.001$ \\
\hline $\begin{array}{l}\text { Local anesthetic volume } \\
\text { (mean, SD) }\end{array}$ & $29.9(3.6)$ & $27.4(4.9)$ & $<0.001$ \\
\hline NRS score (mean, SD) $)^{¥}$ & $5.4(3.6)$ & $4.6(3.8)$ & 0.004 \\
\hline Rescue block $(n, \%)^{\circ}$ & $0(0 \%)$ & $1(0.27 \%)$ & 0.3 \\
\hline Length of stay (mean, SD) & $3.0(1.5)$ & $2.8(1.8)$ & 0.3 \\
\hline $\begin{array}{l}\text { 30-day hospital re- } \\
\text { evaluation following TKA } \\
(\mathrm{n}, \%)^{\Delta}\end{array}$ & $11,2.8 \%$ & $18,4.9 \%$ & 0.1 \\
\hline Inpatient fall events (n, \%) & $0,0 \%$ & $1,0.27 \%$ & 0.3 \\
\hline \multicolumn{4}{|c|}{$\begin{array}{l}\text { DHMC = Dartmouth-Hitchcock Medical Center, TKA = total knee } \\
\text { arthroplasty (primary and revision), THA = total hip arthroplasty (primary } \\
\text { unilateral, } \mathrm{N}=880 \text { ) } \\
{ }^{\Pi} \text { Percentage that were adductor canal blocks by time period } \\
{ }^{\$} \text { Percentage of all blocks that were femoral nerve blocks by time period } \\
\text { (includes both continuous or single shot) }\end{array}$} \\
\hline
\end{tabular}

This article is protected by copyright. All rights reserved 
${ }^{\Delta}$ Percentage of patients who experienced a hospital visit following

discharge for pain related reasons, $\mathrm{N}=880$

$\varepsilon^{\varepsilon}$ Length of stay in days, mean (sd)

${ }^{\epsilon}$ Pre-policy June 1, 2013 to May 31, 2014; Post-policy June 1, 2014 to June 18, 2015

$\neg$ Comparing pre-policy with post-policy; chi square for proportional data; two sample t-test for continuous data

- Rescue blocks defined as blocks placed any time after the surgical procedure.
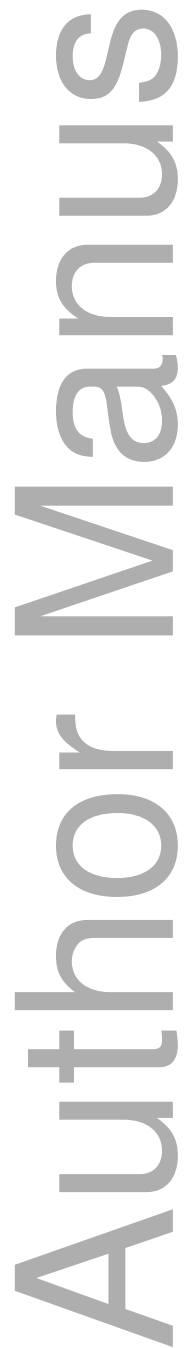

This article is protected by copyright. All rights reserved 


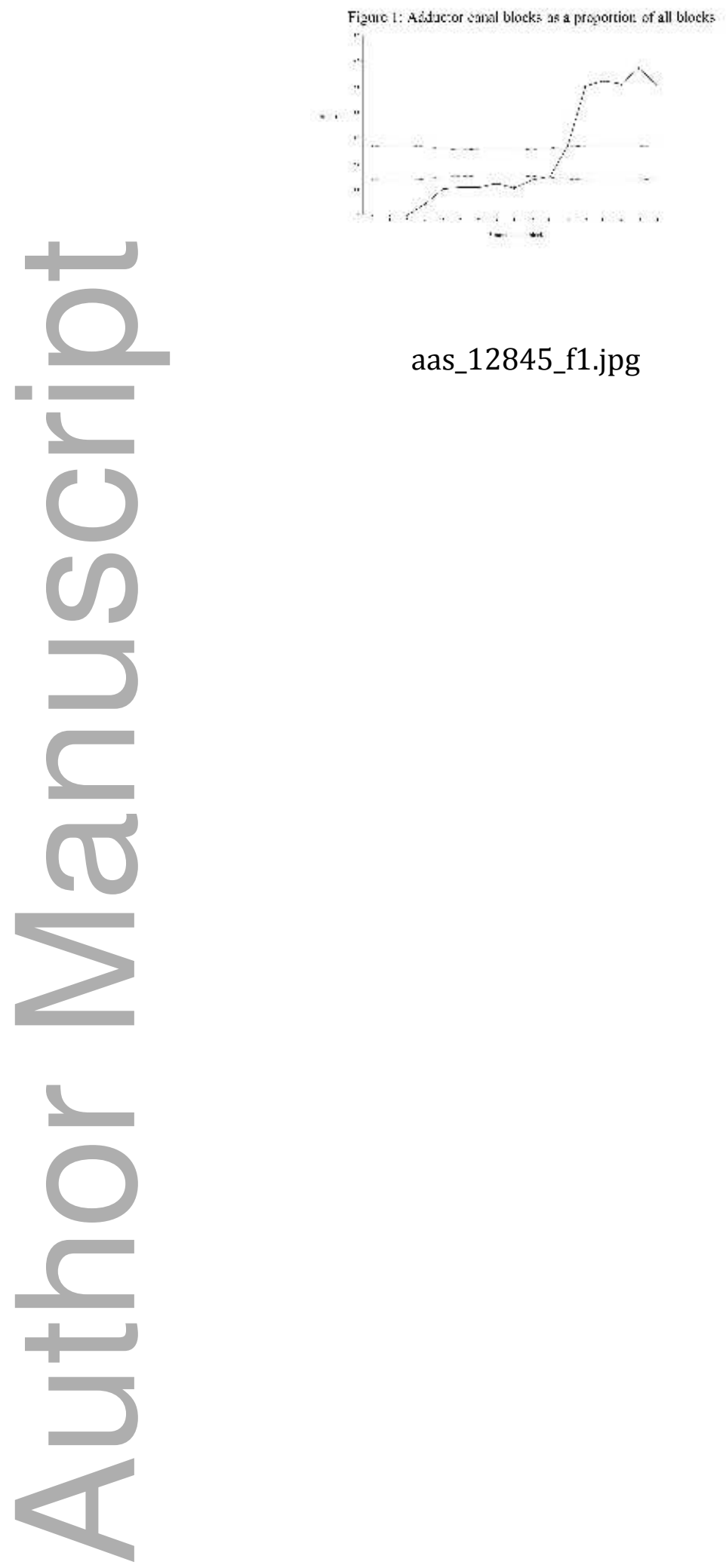

This article is protected by copyright. All rights reserved 

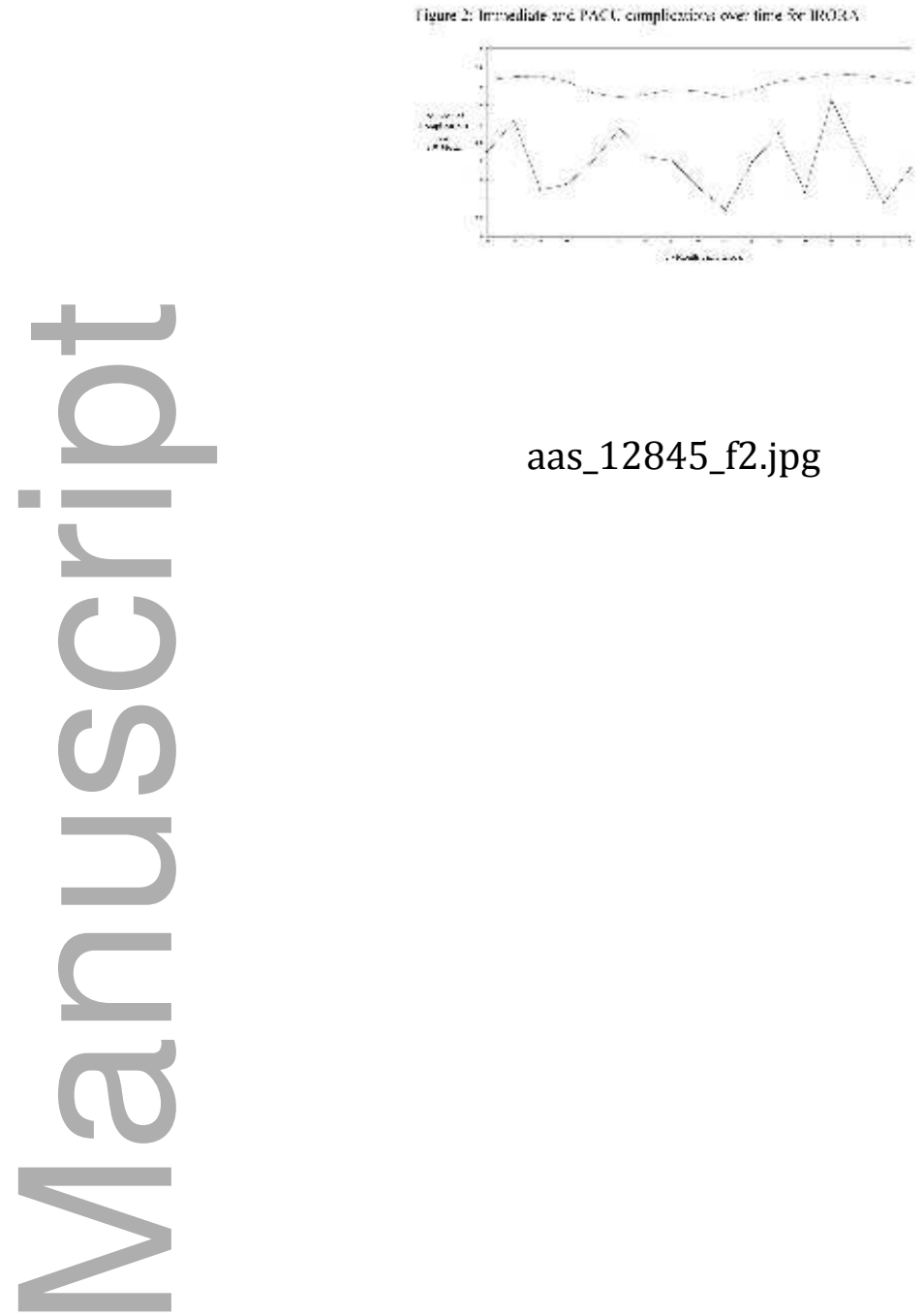

aas_12845_f2.jpg

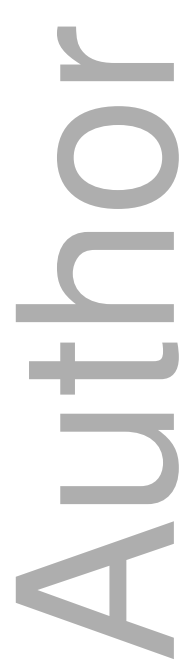

This article is protected by copyright. All rights reserved 


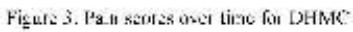

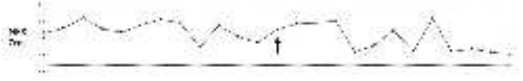

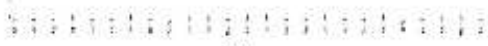

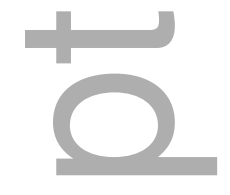

$\square$

aas_12845_f3.jpg
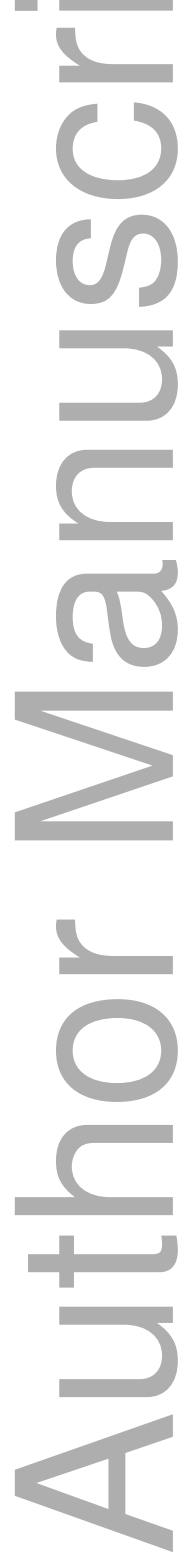

This article is protected by copyright. All rights reserved 


\section{University Library}

\section{- M M N E R VA A gateway to Melbourne's research publications}

Minerva Access is the Institutional Repository of The University of Melbourne

Author/s:

Masaracchia, MM;Herrick, MD;Barrington, MJ;Hartmann, PR;Sites, BD

Title:

Adductor canal blocks: changing practice patterns and associated quality profile

Date:

2017-02-01

Citation:

Masaracchia, M. M., Herrick, M. D., Barrington, M. J., Hartmann, P. R. \& Sites, B. D. (2017). Adductor canal blocks: changing practice patterns and associated quality profile. ACTA ANAESTHESIOLOGICA SCANDINAVICA, 61 (2), pp.224-231. https://doi.org/10.1111/ aas. 12845 .

Persistent Link:

http://hdl.handle.net/11343/292258 